REGARDS

SUR L'ECONOMIE ALLEMANDE

BULLETIN ECONOMIQUE DU CRAC

\section{Regards sur l'économie allemande}

Bulletin économique du CIRAC

112 | 2014

Varia

\title{
Bonheur et croissance
}

\section{(2) OpenEdition}

1 Journals

Édition électronique

URL : https://journals.openedition.org/rea/4663

DOI : 10.4000/rea.4663

ISBN : 978-2-8218-0826-3

ISSN : 1965-0787

Éditeur

CIRAC

Édition imprimée

Date de publication : 28 avril 2014

Pagination : 39

ISSN : 1156-8992

Référence électronique

«Bonheur et croissance», Regards sur l'économie allemande [En ligne], 112 | avril 2014, mis en ligne le 16 mai 2014, consulté le 10 mars 2022. URL : http://journals.openedition.org/rea/4663 ; DOI : https:// doi.org/10.4000/rea.4663

Ce document a été généré automatiquement le 10 mars 2022.

(c) CIRAC 


\section{Bonheur et croissance}

\section{RÉFÉRENCE}

OCDE, How's Life? 2013. Measuring Well-Being, OECD iLibrary, www.oecd-

ilibrary.org, 2013, $210 \mathrm{p}$.

1 La crise de la finance mondiale a semé le doute quant au modèle de vie des sociétés industrielles et aux indicateurs de croissance habituels. Indépendamment ou non du rêve de la «croissance zéro » qui avait vu le jour voici bientôt 50 ans dans le cadre du Club of Rome, la question se pose de plus en plus dans nos sociétés prospères de savoir comment conjuguer bien-être et performance. Dans l'abondante littérature sur cette thématique liée à l'idée de "l'indice du bonheur national brut" appliqué à nos économies, voici plusieurs ouvrages se penchant chacun sur un des nombreux aspects en jeu. Très scientifiquement, le rapport de l'OCDE cherche à identifier des indicateurs permettant de définir (et de suivre) le ressenti du bien-être. Et on ne sera pas étonné de constater que la richesse (personnelle ou celle du PIB) n'est pas nécessairement la clé du bonheur. Dans un autre registre, cette sorte de guide que publie la sociologue et économiste américaine, Juliet $\mathrm{B}$. SCHOR, part du thème désormais classique de « l'enchaînement frénétique » qui accélère course au bonheur et consommation, pour esquisser un mode de vie privilégiant l'épanouissement personnel dont la clé est, selon l'auteur, la réduction du temps de travail. Dans un autre registre, tout aussi anticonsumériste bien que de facture plus récente, deux Français, professeurs d'économie (DE PERTHUIS/JOUVET) se penchent sur le rapport de l'Homme à la Nature - ou plus exactement l'Environnement - et nous proposent un modèle de « croissance verte » à la place des doctrines établies. Mais au fait, comment est née l'idée de la croissance et de la prospérité ? Avec beaucoup d'humour et de sens didactique à la fois, Von WALLWITZ (mathématicien, philosophe et gestionnaire de fonds) nous retrace son cheminement de Voltaire à Keynes en passant par Schumpeter, Rousseau ou Deng Xiaoping. 